\title{
Preparation and Property Evaluation of Nanocomposites Based on Polyurethane-Modified Epoxy/Montmorillonite Systems
}

\author{
M. BAKAR
}

Technical University of Radom, Department of Organic Materials Technology, Radom, Poland $\mathbf{M}$.

\section{KOSTRZEWA}

Technical University of Radom, Department of Organic Materials Technology, Radom, Poland Tomas Bata University in Zlin, Polymer Centre, Z/m, Czec/z Republic

\section{B. HAUSNEROVA}

Tomas Bata University in Zlin, Polymer Centre, Zlin, Czech Republic K. SAR

Technical University ofRadom, Department of Organic Materials Technology, Radom, Poland

\begin{abstract}
Montmorillonite nanoclay and polyurethanes obtained from polyethylene glycol (PUR 400) and polyoxypropylene diol (PUR 1002) were used to enhance the mechanical properties of an epoxy resin. Maximum impact strength improvement was obtained with compositions containing $2 \%$ nanoclay and $10 \%$ PUR 400 as well as that with $1 \%$ nanoclay and $15 \%$ PUR 400 , corresponding to $110 \%$ and $75 \%$, respectively, in relation to the unmodified epoxy resin. Moreover, a 10-fold increase was observed with respect to the flexural strain at break for the composition containing 15\% PUR 1002 and 2\% nanoclay.
\end{abstract}


SEM micrographs have indicated that the mechanism of mechanical property enhancement is associated with increased yield of the epoxy matrix. Moreover, FTIR results showed that some chemical reactions have taken place between the hydroxyl groups of epoxy resin and the isocyanate groups of polyurethane, explaining partly the improvement in the mechanical properties of the polymer matrix. (c) 2010 Wiley Periodicals, Inc. Adv Polym Techn 29: 237-248, 2010; View this article online at wileyonlinelibrary.com. DOI 10.1002/adv.20192

KEY WORDS: Epoxy, Mechanical properties, Nanocomposites, Polyurethanes, Structure

\section{Introduction}

Because of their high-dimensional stability, as well as the very good chemical resistance, epoxy resins are widely used as matrices for high- performance composite materials, surface coatings, and adhesives. However, cured epoxy resins exhibit low impact strength, poor resistance to crack propagation, and low elongation at break.

In the past few decades, a considerable amount of work has been devoted to improve the mechanical and thermal properties of epoxy resins. Approaches to enhance the adhesive and mechanical strength of the final products have included the addition of particulate fillers, ${ }^{1-3}$ reactive liquid rubbers, ${ }^{4-10}$ and thermoplastic polymers. ${ }^{11-15}$ Epoxy resin's properties have also been improved by using nanoparticles ${ }^{16-20}$ as well as other cross-linkable polymers to form full- or semi-interpenetrating polymer networks..$^{21-29}$

Yilmazer and co-workers ${ }^{16}$ have used unmodified montmorillonite (Cloisite $\mathrm{Na}^{+}$) and organically modified Cloisite 30B as reinforcing agents for diglycidyl ether of bisphenol-A (DGEBA), Their results have shown an increase in the glass transition temperature $\left(\mathrm{T}_{\mathrm{g}}\right)$ by more than $10^{\circ} \mathrm{C}$ with the addition of $9 \mathrm{wt} \%$ of a modified montmorillonite (MMT). The addition of 0.5 and $1 \mathrm{wt} \%$ of Cloisite $30 \mathrm{~B}$ resulted in a maximum improvement in the impact strength of DGEBA. The tensile strength also exhibited the maximum value at 1 $\mathrm{wt} \%$ modified clay loading.

In another work, Messersmith and Giannelis ${ }^{17}$ have prepared exfoliated layered silicate epoxy nanocomposite based on DGEBA cured with nadic methyl anhydride in the presence of benzyldimethylamine. Their results have shown a significant increase in the modulus of the epoxy nanocomposite using 4 $w t \%$ of organoclay modified with bis (2-hydroxy ethyl) methyl tallow-alkyl ammonium chloride. The dynamic storage modulus of the nanocomposite containing $4 \mathrm{wt} \%$ silicate was approximately $58 \%$ higher in the glassy region and $450 \%$ higher in the rubbery plateau region compared to that of virgin epoxy.

The mechanism of the exfoliation of the filler was also analyzed by Lan et al. ${ }^{18}$ for nanocomposites based on DGEBA cured with m-phenylenediamine. The exfoliation of the clay was not only dependent on the reactivity of epoxy system but also on the accessibility of the matrix and the curing agent into the clay galleries. Moreover, the exfoliation was facilitated by the exchange of cations, which catalyze the intragallery polymerization of the epoxy resin.

Kornmann et al. ${ }^{19}$ have prepared exfoliated nanocomposites using diglycidyl ether of bisphe- nol A and polyoxyalkylene diamine as a curing agent. They have studied the dependence of the cation-exchange capacities (CEC) on the synthesis and structure of epoxy-nanoclay nanocomposites. The exfoliation of montmorillonite takes place at low CEC during the swelling stage of the epoxy resin, which undergoes homopolymerization during swelling prior to crosslinking reactions because of the large space available between the galleries.

Polyurethanes (PUR) have also been used to improve the toughness of epoxy resins. Wang and Chen ${ }^{20}$ modified diglicydyl ether of Bisphenol A with a PUR prepolymer terminated with aromatic amine groups as well as phenolic hydroxyl groups. The results of their work showed that the epoxy modified with PUR containing phenol hydroxyl groups had higher fracture toughness than the corresponding system containing PUR with amine groups.

Polyurethane chains can be linked to the epoxy network through physical entanglements as well as chemical bonding to form graft interpenetrating polymer network (IPN) structures. Hsieh and Han ${ }^{21}$ have evaluated the mechanical properties of graft IPN of an epoxy and a PUR based on polyols with different chain lengths. The results showed that the 
significant improvement in the tensile strength was related to the grafted structure and to the length of PUR chains. Harani and co-authors ${ }^{22}$ have also proved that the addition of isocyanate-terminated polyurethanes significantly improved the fracture toughness of epoxy resin. Moreover, the use of a chain extender with polyurethane prepolymer caused a sevenfold increase in the impact strength and almost twofold increase in the critical stress intensity factor, $K Q$, in comparison with the unmodified epoxy resin. In a separate work, Park and Jin $^{23}$ have evaluated the mechanical properties, as well as surface free energy, of epoxy resin-polyurethane systems. The polar components of the surface free energy of the composition were largely influenced by the addition of PUR, which caused an increase in $K Q$ and impact strength at low-temperatures. The improvement in the mechanical properties was explained as a result of the increase in the strength of the hydrogen bonds between the hydroxyl groups of the epoxy resin and the isocyanate groups of the PUR.

More recently, we have investigated the effect of polyurethanes having different isocyanate index on the mechanical and thermal properties of epoxy resin. ${ }^{24}$ The largest improvement in the fracture toughness was achieved with the PUR having the highest isocyanate content. The infrared spectra have indicated that the excess of isocyanate groups has produced grafting reactions between the modifier and the epoxy matrix, which explained the observed toughening effect.

The aim of the present work is to investigate the properties and morphology of an epoxy resin modified with polyurethane and reinforced with an organomodified montmorillonite. Reactions are to be expected between the $-\mathrm{CH}_{2} \mathrm{CH}_{2} \mathrm{OH}$ groups of the quaternary ammonium salt in the nanoclay and the isocyanate groups of PUR, enhancing the stability of the nanoclay dispersion after exfoliation.

\section{Experimental}

\section{MATERIALS}

The following components were used in the present work:

- epoxy resin-diglycidyl ether of bisphenol A (Epidian 5, Organika Sarzyna, Nowa Sarzyna, Poland) with a molecular weight of $400 \mathrm{~g} / \mathrm{mol}$, viscosity at $25^{\circ} \mathrm{C}$ around $30 \mathrm{~Pa} \mathrm{~s}$, and epoxy number of 0.49-0.52 mol/100 g;

- triethylenetetramine hardener (trade name $\mathrm{Zl}$, Organika Sarzyna, Nowa Sarzyna, Poland);

- polyethylene glycol with molecular weight of 400 $\mathrm{g} / \mathrm{mol}$ (PEG 400) and $277 \mathrm{mg} / \mathrm{g}$ hydroxyl number (Merck, Darmstadt, Germany);

- polyoxypropylene diol with $1000 \mathrm{~g} / \mathrm{mol}$ molecular weight (POPD 1002) and hydroxyl number of $180 \mathrm{mg} / \mathrm{g}$ (Rokita, Poland);

- 2,4-toluene diisocyanate (TDI) for synthesis produced by Merck (Germany);

- dibutyltin dilaurate catalyst (Merck, Germany);

- montmorillonite nanoclay modified with tallowquarternary ammonium salt (Cloisite 30B, Southern Clay Products Inc., Gonzales, TX); and

- toluene and acetone solvents (Merck, Germany).

\section{SYNTHESIS OF POLYURETHANE}

Two types of polyurethanes were prepared from toluene di-isocyanate (TDI) and polyols, based on polyethylene glycol (PUR 400) and polyoxypropylene diol (PUR 1002).

First, $50 \mathrm{~g}$ of polyol and $0.25 \mathrm{~cm}^{3}$ of dibutyltin dilaurate were mixed with a mechanical stirrer for 15 min under vacuum and then heated to $40^{\circ} \mathrm{C}$. One half of the amount of TDI was added dropwise over $15 \mathrm{~min}$. The reaction was then carried in a nitrogen atmosphere for $30 \mathrm{~min}$, while the temperature was maintained below $60^{\circ} \mathrm{C}$. Then, the PUR was cooled to $25^{\circ} \mathrm{C}$ and 50 $\mathrm{cm}^{3}$ of acetone was added to reduce the viscosity of the mixture. Finally, the rest of TDI was added dropwise for another $15 \mathrm{~min}$ and the temperature of the mixture was maintained below $40^{\circ} \mathrm{C}$.

For $50 \mathrm{~g}$ of polyol, we needed $45.1 \mathrm{~g}$ TDI for PUR 400 and $29.3 \mathrm{~g}$ for PUR 1002, to obtain a PUR having an isocyanate index of 1.05 . The polyols were purified by azeotropic vacuum distillation of toluene to remove the water.

\section{PREPARATION OF POLYURETHANE- MODIFIED EPOXY RESINS AND EPOXY- MONTMORILLONITE COMPOSITES}

The polyurethane was mixed with the epoxy resin in amounts of $5,10,15$, and $20 \mathrm{wt} \%$ using a 
homogenizer for $20 \mathrm{~min}$ at a rotational speed of 2500 $\mathrm{rpm}$, at room temperature. The mixtures were then placed in a vacuum oven to remove air bubbles. The curing agent was then added, and mixing was continued for $5 \mathrm{~min}$ before pouring the obtained compositions into the cavities of a mold to produce specimens for mechanical tests. The curing reactions were carried out at room temperature for $48 \mathrm{~h}$ followed by postcuring for $3 \mathrm{~h}$ at $80^{\circ} \mathrm{C}$.

The epoxy-MMT composites were prepared using 1, 2, and $3 \mathrm{wt} \%$ of Cloisite 30B (MMT). $10 \mathrm{~g}$ of MMT was added to $40 \mathrm{~cm}^{3}$ of acetone to disperse the nanoclay and then poured in a preheated epoxy resin $\left(40^{\circ} \mathrm{C}\right)$, followed by mechanical stirring for $15 \mathrm{~min}$ at 2500 rpm. After homogenization, the epoxy-based mixtures were placed in a vacuum oven to remove air bubbles and the residual solvent. Finally, the curing agent was admixed and the mixtures were poured into the cavities of the mold. Curing and postcuring were carried out under the same conditions as described for epoxy/PUR compositions.

\section{PREPARATION OF EPOXY NANOCOMPOSITES MODIFIED WITH POLYURETHANE}

Compositions containing 1 and $2 \mathrm{wt} \%$ Cloisite 30B and different amounts of PUR were prepared. First, the solvent dispersion with a specific amount of MMT was mixed with epoxy resin for $20 \mathrm{~min}$ prior to the PUR incorporation and mixture homogenization. After degassing in a vacuum oven, the curing agent was added and the compositions were placed in the mold. Curing and postcuring processes were carried out as described previously

\section{MECHANICAL PROPERTIES \\ MEASUREMENTS}

Impact strength was measured according to Charpy method using a Zwick 5012 apparatus (ISO 179) on rectangular-shaped samples $(80 \mathrm{~mm}$ long, $10 \mathrm{~mm}$ wide, $4 \mathrm{~mm}$ thick, with a $1-\mathrm{mm}$ notch).

Three-point bending tests (ISO 178) were carried out at room temperature on specimens of the same dimensions as for impact tests using an Instron 5566 at deformation rate of $5 \mathrm{~mm} / \mathrm{min}$. The distance between the spans was $60 \mathrm{~mm}$.

The critical stress intensity factor $K_{Q}$ was evaluated using Eq. (1) by means of three-point bending tests on notched $(1 \mathrm{~mm})$ specimens having the same dimensions as impact. The test was carried out using an Instron 5566 with a deformation rate of 5 $\mathrm{mm} / \mathrm{min}$ and a distance between the spans of $60 \mathrm{~mm}$ [25]:

$$
K_{\mathrm{C}}=\frac{3 \cdot P \cdot L \cdot a^{1 / 2}}{2 B \cdot w^{2}} Y\left(\frac{a}{w}\right)
$$

where $\mathrm{P}$ stands for load at break, L represents spans distance, $a$ is notch length, $w$ stands for sample width, $B$ is sample thickness, and $Y$ means a geometry factor.

The geometry factor was calculated according to the following equation ${ }^{25}$ :

$$
\begin{aligned}
Y\left(\frac{a}{w}\right)= & 1.93-3.07 \cdot\left(\frac{a}{w}\right)+14.53 \cdot\left(\frac{a}{w}\right)^{2} \\
& -25.11 \cdot\left(\frac{a}{w}\right)^{3}+25.80 \cdot\left(\frac{a}{w}\right)^{4}
\end{aligned}
$$

\section{CHARACTERIZATION}

Infrared spectroscopy (FTIR) was performed on a Perkin-Elmer spectrophotometer (1000 PC) recording the IR spectra from 450 to $4000 \mathrm{~cm}^{-1}$. Scanning electron microscope (Hitachi S-2460 N) was employed to examine the fracture surfaces of specimens obtained from the impact tests. X-ray diffraction (XRD) tests were performed using X' PERT PRO Pan- alytical X-ray diffractometer with a $\mathrm{Cu} K_{a} \mathrm{i}=1.54 \mathrm{~A}$ radiation source operating at $40 \mathrm{kV}$ and $30 \mathrm{~mA}$.

Differential scanning calorimetric (DSC) tests were carried out on a Pyris 1 Perkin-Elmer apparatus to measure the $\mathrm{T}_{\mathrm{g}}$ of selected compositions. The scan rate was $10^{\circ} \mathrm{C} / \mathrm{min}$ within a temperature ranging from -25 to $200^{\circ} \mathrm{C}$ under nitrogen atmosphere. The $\mathrm{Tg}$ was taken at the median point in the range of glass transition.

\section{Results and Discussion}

\section{MECHANICAL PROPERTIES}

The impact strength (IS), the critical stress intensity factor $(K Q)$, and the flexural properties (stress at break, the strain at break, and the energy at break) are measured for epoxy resin containing different amounts of montmorillonite (MMT). The obtained results are summarized in Table I. It can be noted that the IS and $K Q$ values increase with increasing amount of MMT. These properties were improved 
TABLE I

Properties of Epoxy-Based Compositions Containing Different Amounts of Montmorillonite

\begin{tabular}{lccccc}
$\begin{array}{l}\text { MMT } \\
\text { Content } \\
(\mathrm{W} 1 \%)\end{array}$ & $\begin{array}{c}\text { Impact } \\
\text { Strength } \\
\left(\mathrm{kJ}^{2} / \mathrm{m}^{2}\right)\end{array}$ & $\left.\begin{array}{c}K_{\mathrm{C}} \\
(\mathrm{MFa}\end{array} \mathrm{m}^{1 / 2}\right)$ & $\begin{array}{c}\text { Stress at } \\
\text { Break } \\
(\mathrm{MPa})\end{array}$ & $\begin{array}{c}\text { Strain at } \\
\text { Break } \\
(\mathrm{m} / \mathrm{m})\end{array}$ & $\begin{array}{c}\text { Energy at } \\
\text { Break } \\
\left(\mathrm{kJ} / \mathrm{m}^{2}\right)\end{array}$ \\
\hline 0 & 1.0 & 1.2 & 41.2 & 0.005 & 4.3 \\
1 & 1.5 & 2.2 & 54.6 & 0.019 & 3.7 \\
2 & 1.4 & 2.1 & 77.3 & 0.020 & 5.9 \\
3 & 1.4 & 2.0 & 44.1 & 0.015 & 2.3 \\
\hline
\end{tabular}

up to $50 \%$ and $85 \%$, respectively, for the composition containing $1 \mathrm{wt} \%$ MMT in comparison to the neat epoxy resin. The composition containing $2 \mathrm{wt} \% \mathrm{MMT}$ shows the highest flexural properties (both flexural strength and strain at break) in comparison with the nonreinforced epoxy samples, showing a twofold and fourfold increase in the flexural strength and strain at break. Moreover, the fracture energy, expressed as the area under the force/deflection curve, increased from 4.3 to $5.9 \mathrm{~kJ} / \mathrm{m}^{2}$.

The decrease in the tensile strength and flexural energy at break exhibited by the epoxy resin nanocomposite containing $3 \mathrm{wt} \%$ MMT could be due to the presence of nanoclay particles aggregates.

Our previous results ${ }^{26}$ have confirmed that the addition of polyurethanes (PUR 400 and PUR 1002) produces a large increase in impact strength and $K Q$ values. The IS values were increased by approximately $130 \%$ upon addition of $15 \mathrm{wt} \%$ PUR 400, whereas KQ increased by approximately $150 \%$ when $10 \mathrm{wt} \%$ PUR obtained from Rokopol D1002 (PUR 1002) was added.

It is in light of these results that these two types of polyurethanes (i.e., PUR 400 and PUR 1002) were chosen to prepare the modified epoxy nancompos- ites (i.e., epoxy resin modified with MMT, PUR 400 and PUR 1002).

In Fig. 1, the effect of the PUR 400 modification on the impact strength of the epoxy nancomposites with 1 and $2 \mathrm{wt} \%$ of montmorillonite is shown. These results show that the addition of both polyurethane and montmorillonite improves the impact strength of epoxy resin. All modified compositions exhibited higher impact strength than the unmodified epoxy resin. However, the best results were obtained with epoxy nancomposite containing $2 \mathrm{wt} \%$ MMT and 10 wt $\%$ PUR 400 as well as that with $1 \mathrm{wt} \%$ MMT and 15 wt $\%$ PUR 400, representing $110 \%$ and $75 \%$ improvement, respectively, in relation to the virgin epoxy resin (composition 0/0).

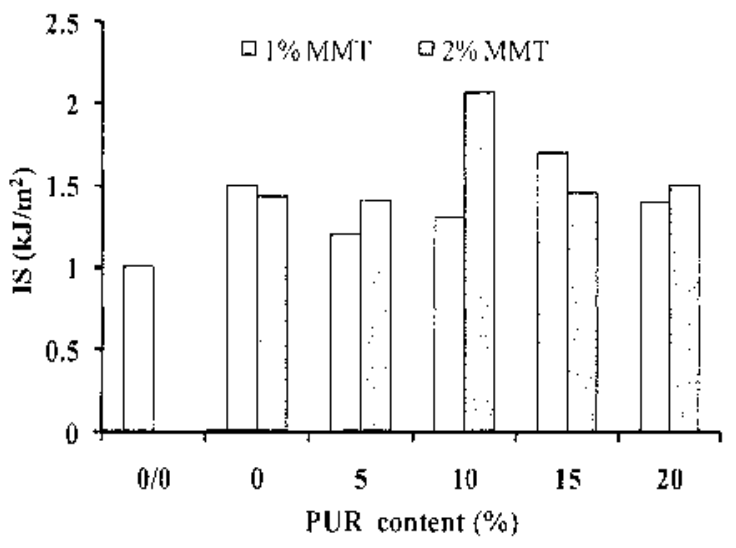

FIGURE 1. IS of modified epoxy nanocomposites as a function of polyurethane (PUR 400) content.

The improvements in the impact strength can be attributed to the good dispersion of nanoclay particles, as well as to the intrinsic properties of the modified epoxy resin network.

In Fig. 2, the impact strength of the modified epoxy nanocomposites containing PUR 1002 is shown. However, all compositions exhibited higher impact strength values than the base (0/0) epoxy resin without modifier. Comparing these results with those shown in Fig. 1, it can be noted that the polyurethane with longer flexible segments did not cause a significant improvement in the impact strength of the nanocomposites.

Chen and Evans ${ }^{27}$ have shown that higher molecular mass fractions of polymer intercalate preferentially into clay during the nanocomposite

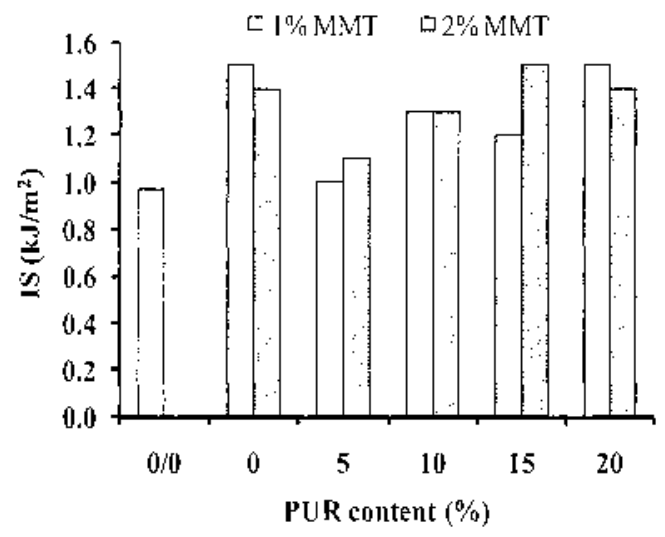

FIGURE 2. IS of epoxy nanocomposites as a function of polyurethane (PUR 1002) content. 


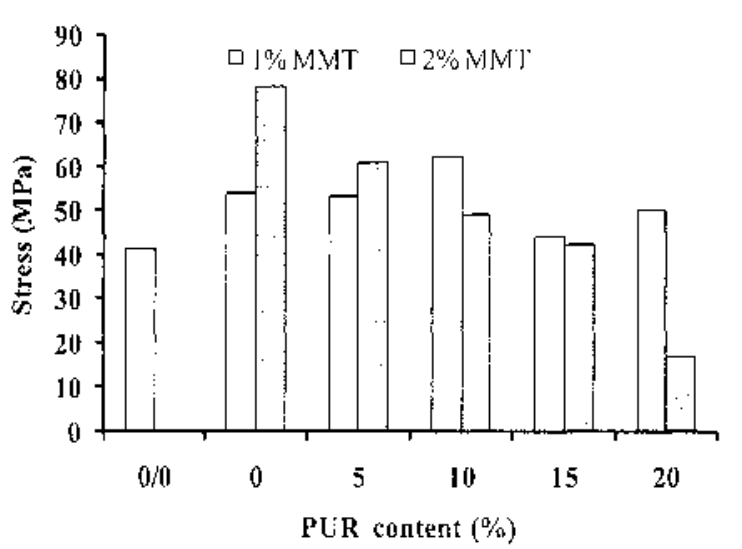

FIGURE 3. Effect of polyurethane (PUR 400) modification on the flexural stress at break of epoxy nanocomposites with $1 \%$ and $2 \%$ MMT.

preparation and, therefore, this could explain the effect reported above.

The stress at break values measured in the threepoint bending test is shown in Figs. 3 and 4 for nanocomposites based on both PUR 400 and PUR 1002. From these data, it can be observed that maximum strength improvement was obtained for epoxy hybrid nanocomposites containing $10 \mathrm{wt} \%$ PUR and $1 \mathrm{wt} \%$ MMT.

The strength improvements achieved are $50 \%$ and $25 \%$, in comparison, respectively, to neat epoxy resin and $1 \mathrm{wt} \% \mathrm{MMT} / \mathrm{epoxy}$ resin nanocomposites.

From the results shown in Fig. 4, one can observe that the incorporation of the polyurethane

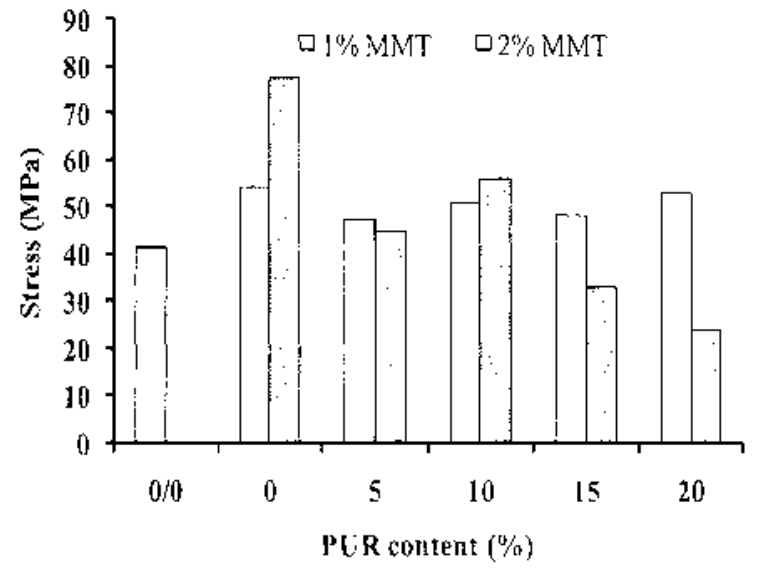

FIGURE 4. Effect of polyurethane (PUR 1002) modification on flexural stress at break of epoxy nanocomposites with 1 and $2 \% \mathrm{MMT}$. synthesized from polyoxypropylene diol (PURI002) did not show a significant effect on the flexural strength of epoxy nanocomposite containing $1 \mathrm{wt} \%$ of montmorillonite. Moreover, the epoxy nanocomposite based on $2 \mathrm{wt} \%$ MMT and containing $5 \%$ and $10 \%$ PUR exhibits higher flexural strength than virgin epoxy compositions. However, similarly to PUR 400 nancomposites (Fig. 3), a deterioration effect can be noted for nancomposites with $2 \mathrm{wt} \%$ MMT.

Therefore, it seems that the incorporation of polyurethane with long flexible segments leads to an improvement in flexural strength without significant deterioration of the impact strength. However, the polyurethane with shorter segments and low molecular weight contributes more effectively to impact strength improvement.

A decrease in the flexural strength of epoxy nanocomposites based on 2\% MMT and higher polyurethane content might be related to the reduction in the interaction between the epoxy resin and the incorporated modifiers.

In Fig. 5, it is shown that the flexural strain at break increases with increasing PUR content. The highest value (10 times higher than that of original epoxy resin) was obtained for nanocomposites containing 15\% PUR 1002 and MMT. However, the flexural strain at break increased to 165 and $125 \%$ levels, respectively, with 2 and 1 wt $\%$ MMT in comparison with the flexural strain of epoxy nanocomposites containing, respectively, $2 \mathrm{wt} \% \mathrm{MMT}$ and that with $1 \mathrm{wt} \%$ MMT. The incorporation of relatively long flexible PUR chains to epoxy resin contributes to more movements, thus allowing the samples to reach higher strains before fracture occurs.

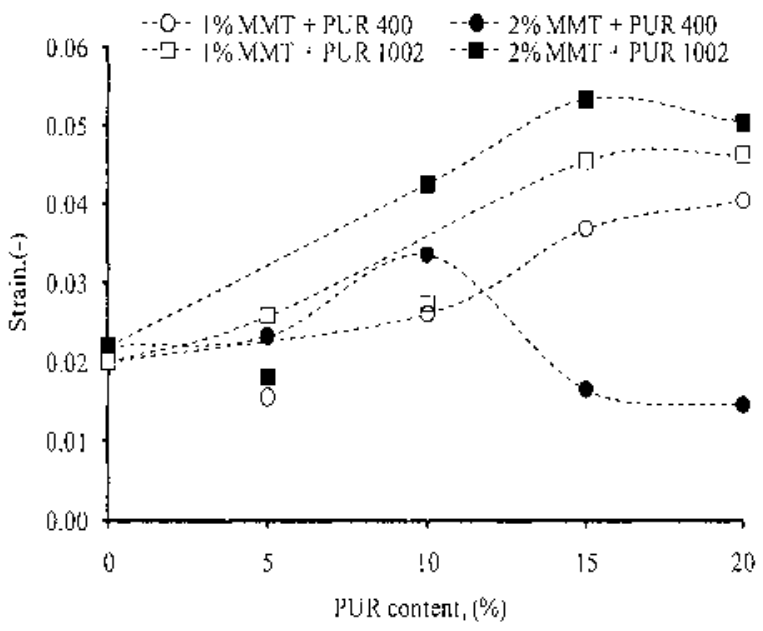

FIGURE 5. Effect of PUR content on flexural strain of epoxy nanocomposites with $1 \%$ and $2 \%$ MMT. 


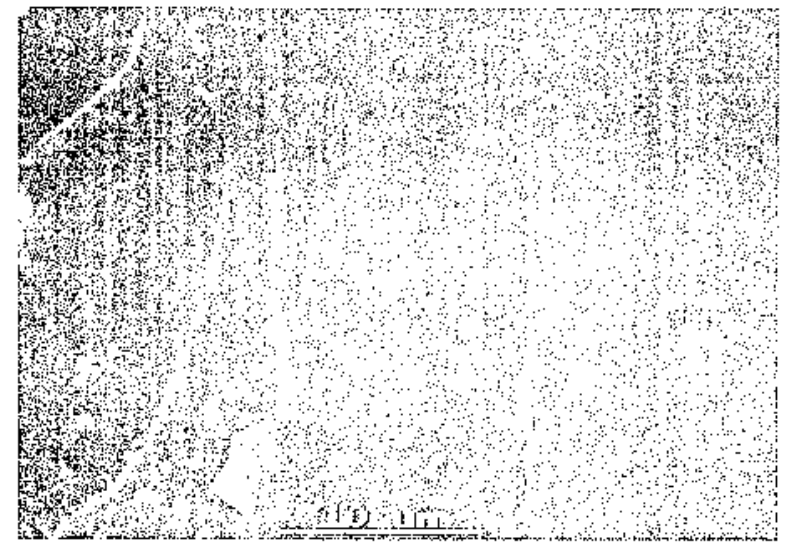

FIGURE 6. SEM micrograph of an unmodified epoxy resin.

Nevertheless, these results demonstrate the need to use less nanoclay within the polymer matrix to obtain epoxy nanocomposites with enhanced properties.

\section{FRACTURE SURFACE ANALYSIS}

SEM micrographs obtained from fracture surfaces of pristine samples and compositions containing polyurethanes based on polyethylene glycol and polyoxypropylene diol can help to understand the toughening mechanism induced by PUR incorporation. All obtained micrographs were scanned on samples after impact tests near the crack tip.

The micrograph of the unmodified epoxy composition fracture surface is flat and glassy (Fig. 6), indicating the occurrence of regular uninterrupted and an elastic crack propagation path.

In Fig. 7, a micrograph of the epoxy resin composites containing $1 \%$ MMT is shown. The fractured surface is rough and contains larger domains. The concomitant addition of MMT and 10\% PUR based on polyethylene glycol 400 (PUR 400) gave a more stratified elongated structure between epoxy resin and modifier (Fig. 7b).

However, the micrographs in Figs. $8 \mathrm{a}$ and $8 \mathrm{~b}$ show a rather different structure for systems with the incorporation of PUR 1002, when compared with the micrograph for the pure epoxy resin (Fig. 6), the surface is no more smoother but reveals the presence of elongated domains. This may explain the higher values of the flexural strain at break as shown in Fig. 5 as well as the resistance to crack propagation as expressed by $K Q$ and the impact strength data. The occurrence of plastic yielding and the formation of the second phase within the polymer matrix are usually associated with higher energy absorption during the crack propagation processes either under impact or low-speed conditions.

Figure 9 shows SEM micrographs of epoxy nanocomposites (2 wt\% MMT) modified with $10 \mathrm{wt} \%$ PUR 400 (Fig. 9a) and 15 wt\% PUR 1002 (Fig. 9b). The composition containing PUR 400 has a more stratified structure due to MMT particles surrounded by the polymer matrix. The SEM micrograph shows the phase separation, i.e., larger number of microvoids, which could be the reason for the observed decrease in the fracture toughness. This composite also exhibits a lower value of the impact strength in comparison with composite containing

$1 \mathrm{wt} \%$ of MMT.

It can be mentioned that the structure of epoxy nanocomposite based on $2 \mathrm{wt} \%$ MMT and $15 \mathrm{wt} \%$ PUR 1002 (Fig. 9b) is similar to that of nanocomposite containing $1 \mathrm{wt} \%$ MMT and $10 \mathrm{wt} \%$ PUR 400 as depicted in Fig. $7 \mathrm{~b}$. These nanocomposites also exhibit a lower value of the impact strength in comparison with nanocomposites containing $1 \mathrm{wt} \%$ of MMT.

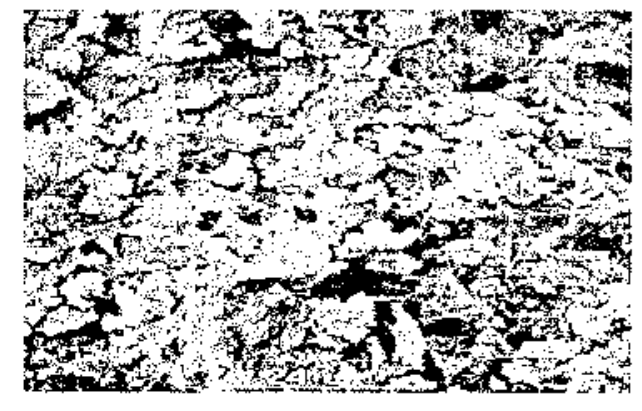

(i)

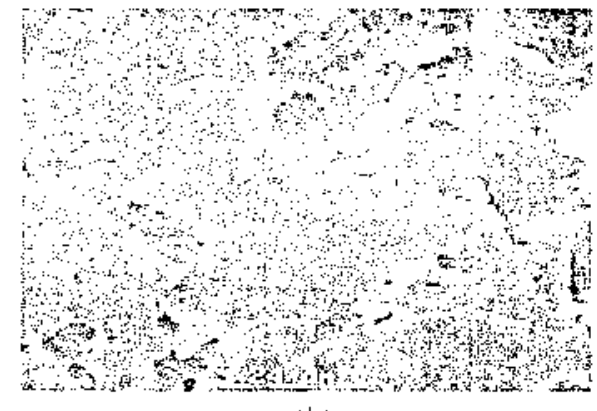

(is)

FIGURE 7. SEM micrograph of an epoxy resin modified with (a) $1 \%$ MMT and (b) $1 \%$ MMT and 10\% PUR 400. 


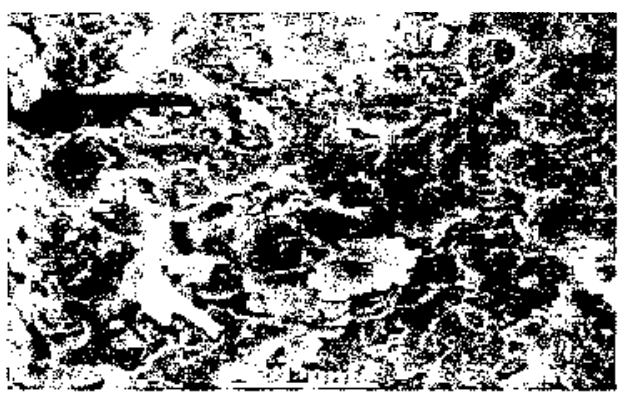

i

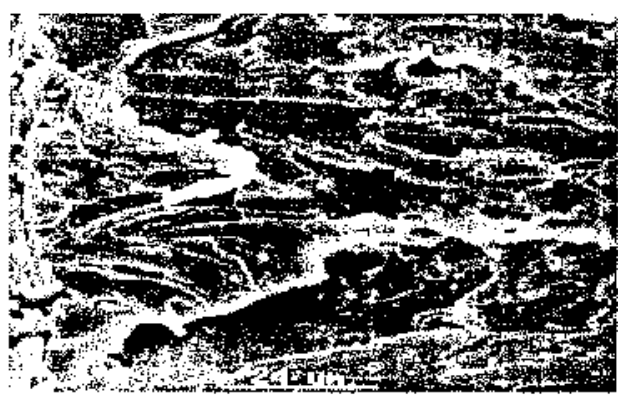

iti

FIGURE 8. SEM micrograph of epoxy nanocomposites (1\% MMT) modified with (a) 15\% PUR 1002 and (b) $20 \%$ PUR 1002.

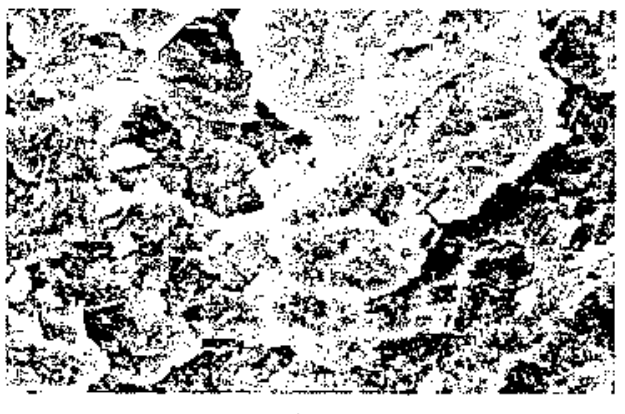

(is)

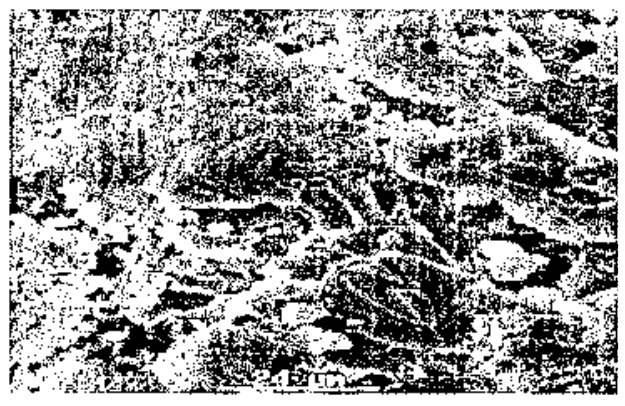

(b)

FIGURE 9. SEM micrographs of epoxy nanocomposites (2\% MMT) modified with (a) 10\% PUR 400 and (b) 15\% PUR 1002.

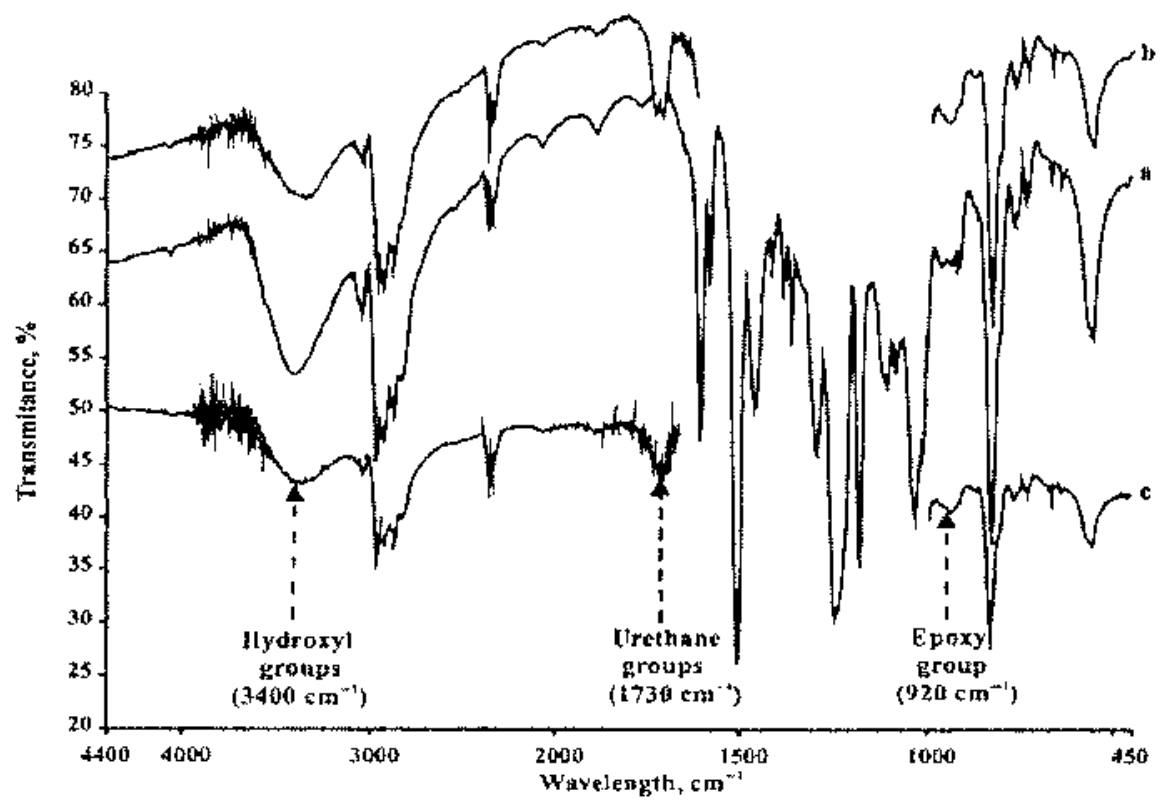

FIGURE 10. FTIR spectra of virgin epoxy resin (a) and modified compositions containing 10\% PUR 400 (b) and $15 \%$ PUR 1002 (c). 
TABLE II

Peak Heights of Hvdroxvl Groups of Selected Epoxv Resin Based Compositions

\begin{tabular}{lccr} 
Composition & Peak Height (\%T) & Composition & Peak Height (\%) \\
\hline Virgin EP & 11.4 & Virgin EP & 11.4 \\
EP + 10\% PUR 400 & 5.9 & EP + 1\% MMT & 7.7 \\
EP + 15\% PUR 1002 & 3.8 & EP $+2 \%$ MMT $+10 \%$ PUR 400 & 6.0 \\
& & EP + 2\% MMT + 15\% PUR 1002 & 3.2 \\
\hline
\end{tabular}

\section{STRUCTURE CHARACTERIZATION}

The FTIR spectra of compositions containing polyurethanes (PUR 400 and PUR 1002) are shown in Fig. 10 together with that of virgin epoxy resin. The epoxy resin modification with PUR 400 shows a decrease in the hydroxyl group peak intensity (as shown in Table II) approximately by $50 \%$ and peak area by $44.4 \%$ in comparison with neat epoxy resin. This may arise from the reactions taking place between isocyanate groups of polyurethane and hydroxyl groups of epoxy resin, as indicated by the absence of the isocyanate peak at $2270 \mathrm{~cm}^{-1}$ and is illustrated in Scheme 1. Moreover, the appearance of the peak at $1730 \mathrm{~cm}^{11}$ confirms the presence of the allophonate and urethane groups in the epoxy compositions containing polyurethanes (PUR 400 and PUR 1002).

Thus, the FTIR spectra confirm the presumption of the improvement in mechanical properties due to the formation of grafted IPN structures within this composition.

The incorporation of PUR 1002 resulted in a decrease in the hydroxyl groups peak height by $65 \%$ and peak area by $64.4 \%$ in relation to neat epoxy resin, confirming the occurrence of interchain bonds between polyurethane and epoxy resin. Moreover, the epoxy group peak appearing at $920 \mathrm{~cm}^{-1}$ has an intensity similar to that found in both epoxy resin and the resin modified with PUR 400.

Zheng and co-workers ${ }^{28}$ found that the addition of organically modified montmorillonite to epoxy/polyurethane IPNs systems promotes the compatibility of epoxy and polyurethane. Moreover, they confirmed that the degree of nanoclay disper sion is improved and results in modified nanocomposites with excellent mechanical properties.

In Fig. 11, the FTIR spectra of neat epoxy resin and nanocomposites (2\% MMT) modified with $10 \mathrm{wt} \%$ PUR 400 and $15 \mathrm{wt} \%$ PUR 1002 are depicted. It can be observed that, for the nanocomposite containing $10 \%$ PUR 400 and PUR 1002, the peak connected with hydroxyl groups has lower intensities (Table II) than that arising from the unmodified epoxy resin. The decrease in the peak heights attained, respectively, $50 \%$ and $70 \%$ in comparison with an unreinforced epoxy resin. On the other hand, the peak areas decreased by, respectively, $44.2 \%$ and $11.5 \%$.

This can be related to the formation of bonding between the free isocyanate groups from polyurethane and hydroxyl groups from epoxy, resulting in the formation of grafted IPN structure in the examined composition, which is responsible for the increase in the impact strength and flexural strength (see Scheme 1).

Table II contains values of peak heights of hydroxyl groups of selected epoxy resin compositions containing different amounts of polyurethanes and montmorillonite.

The X-Ray diffraction method is used to characterize the nanoclay structure within the epoxy nanocomposites. From Fig. 12 showing the XRD patterns of selected epoxy nanocomposites containing MMT, PUR 400, and PUR 1002, it can be seen that for epoxy nanocomposite containing only $2 \mathrm{wt} \%$ MMT the $\mathrm{d}$-spacing value of the clay in the epoxy resin, estimated from the Bragg equation at 20 of $5.3^{\circ}$, is 1.7 $\mathrm{nm}$. Moreover, the lack of distinct diffraction peaks in the range 2.5-10.5 in the XRD pattern is<smiles>CCCCCC(=O)Nc1ccc(N=C=O)cc1N=C=O</smiles>

SCHEME 1. 


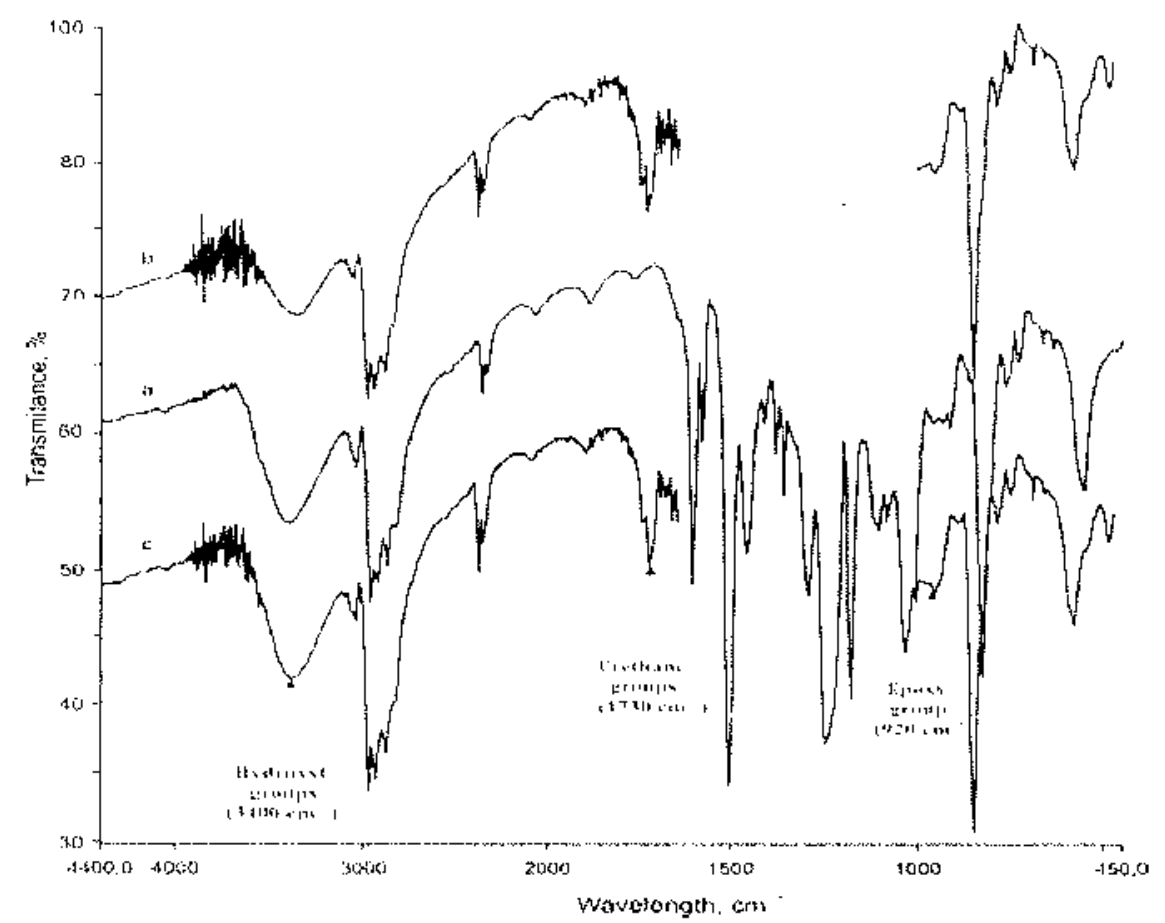

FIGURE 11. FTIR spectra for neat epoxy resin (a), epoxy resin modified with $2 \%$ MMT and $10 \%$ PUR 400 (b), and composite containing 2\% MMT and 15\% PUR 1002 (c).

observed, thus confirming the randomization or exfoliation structure of the nanoclay. Similar results were reported by other researchers. ${ }^{29}$ Furthermore, the incorporation of $10 \mathrm{wt} \%$ of polyurethane to the nanocomposite ( $2 \% \mathrm{MMT})$ resulted in the disappear-

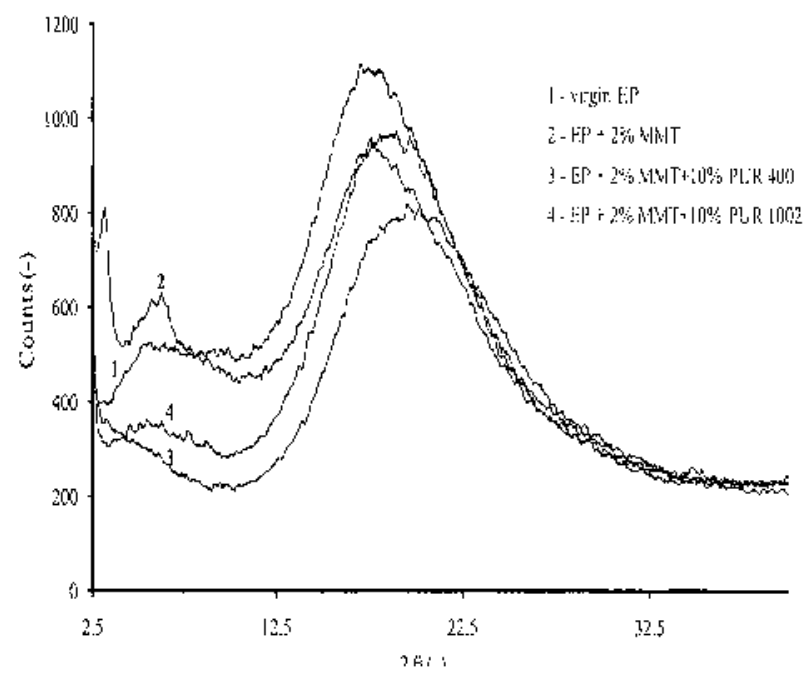

FIGURE 12. XRD patterns of epoxy resin (EP) containing montmorillonite (MMT) and different polyurethane (PUR). ance of peaks in low values of 20 in the range $2.5^{\circ}$ $12.5^{\circ}$. One can confirm the presence of an intercalated structure for the composition containing only MMT and an exfoliated structure for the PUR-epoxy nanocomposites.

The peak that appears at 20 of about $20^{\circ}$ for all nanocomposites as well as for the virgin epoxy resin is usually associated with the amorphous structure of epoxy resin. ${ }^{29,30}$ It can be noted that the addition of PUR promotes the exfoliation process of MMT.

Furthermore, modified montmorillonite contains quaternary ammonium ions with two hydroxyethyl groups capable of reacting with the isocyanate groups of polyurethane according to Scheme 2 .

Such reactions promote the exfoliation of montmorillonite and consequently lead to improvement in mechanical properties of epoxy resin.

It is well known that nanoclay exfoliation is a complex process, which depends on many factors, and involves polymer chain penetration into the nanoclay galleries as well as the development of mechanical stresses during the cross-linking reaction of epoxy resin. ${ }^{31-33}$ Acetone, which was used as a dispersing agent for nanoclay, can easily penetrate clay galleries and enable epoxy resin to be placed between clay layers before the curing process. 


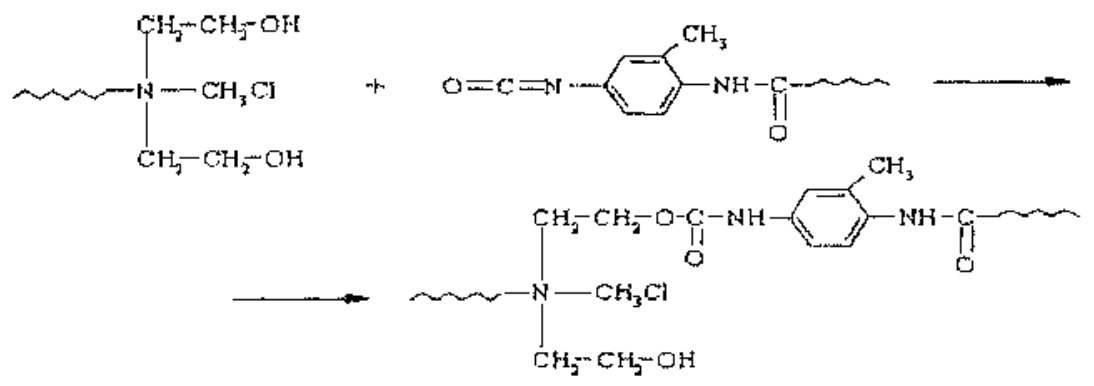

SCHEME 2.

During the cross-linking reaction, a three- dimensional network structure was formed with an exfoliated epoxy/nanoclay nanocomposite.

Chen et al. ${ }^{31}$ used a acetone-clay slurry to prepare a highly exfoliated epoxy nanocomposite. Their results confirmed the ease of epoxy resin penetration into clay galleries as well as its accelerated curing process. Moreover, Park and Jana ${ }^{32}$ explained the nanoclay exfoliation by the elastic force exerted by the crosslinked molecules of epoxy resin inside the galleries.

Table III summarizes the values of the $\mathrm{T}_{\mathrm{g}}$ of epoxy resin as a function of MMT and PUR contents. It is shown that the addition of $1 \mathrm{wt} \%$ of montmorillonite leads to a decrease in the $\mathrm{T}_{\mathrm{g}}$ of epoxy resin by $3.5^{\circ} \mathrm{C}$. An even larger decrease in $\mathrm{T}_{\mathrm{g}}\left(8.4^{\circ} \mathrm{C}\right)$ can be observed when using $2 \mathrm{wt} \%$ MMT loading. Such findings, reported also by other researchers, ${ }^{28,29}$ arise from the reduction in the cross-linking density due to the absorption of the hardener.

However, the incorporation of $5-10 \%$ of linear polyurethane (PUR 400 or PUR 1002) to the epoxy nanocomposites brings about an increase in $\mathrm{T}_{\mathrm{g}}$, in relation to the epoxy nanocomposites containing only MMT. This can be explained by the formation of a grafted IPN structure but also by the increase of crosslink density of the epoxy resin, as already confirmed by FTIR results.

\section{Conclusions}

A series of epoxy nanocomposites were prepared and tested. All nanocomposites showed higher impact strength than the unmodified epoxy resin. The highest increase in the impact strength was obtained for nanocomposites containing $2 \%$ MMT and $10 \%$ PUR 400 , representing $110 \%$ enhancement in comparison with the unmodified epoxy resin. A 10-fold increase in relation to pristine epoxy resin samples was observed for the flexural strain of a nanocomposites containing 15\% PUR 1002 and 2\% MMT. Moreover, the addition of $10 \%$ PUR 400 to $1 \%$ MMT modified epoxy resin resulted in the highest improvement in the flexural strength.

The FTIR results showed that chemical reactions have occurred between the hydroxyl groups of the epoxy resin and the isocyanate groups of the polyurethane modifier, explaining the improvement in the fracture toughness of the polymer matrix. Moreover, SEM micrographs have indicated that the concomitant addition of $1 \%$ MMT and $10 \%$ PUR based on polyethylene glycol 400 (PUR 400) gave a more stratified elongated structure between epoxy resin and modifier as indicated by the rough surface and the presence of larger domains. However, the incorporation of PUR 1002 to epoxy nanocomposite

TABLE II

Glass Transition Temperatures for Selected Epoxy Compositions

\begin{tabular}{|c|c|c|c|}
\hline Formulations & $T_{g}\left({ }^{c} \mathrm{C}\right\}$ & Formulations & $\operatorname{Tg}(\mathrm{C})$ \\
\hline EP & 67.5 & & \\
\hline $1 \% \mathrm{MMT}+\mathrm{EP}$ & 64.0 & $2 \% \mathrm{MMT}+\mathrm{EP}$ & 59.1 \\
\hline $1 \%$ MMT+10\% PUR 400 & 65.6 & $2 \% \mathrm{MMT}+10 \% \mathrm{P} \cup \mathrm{R} 400$ & 68.8 \\
\hline $1 \%$ MMT $+15 \%$ PUR 1002 & 66.1 & $2 \% \mathrm{MMT}+15 \%$ PUR 1002 & 66.5 \\
\hline
\end{tabular}


(1\% MMT) showed a rather different structure with elongated domains, which could be associated with the increase in the impact strength and $K Q$ values.

The DSC results showed a slight decrease in the $\mathrm{Tg}_{\mathrm{g}}$ with the addition of MMT, most probably due to a reduction in the cross-linking density of the polymer matrix. The XRD analysis has confirmed the formation of intercalated structure for the compositions containing only MMT and an exfoliated structure for the related nanocomposites.

\section{References}

1. Lange, F. F.; Radford, K. C. J Mater Sei 1971, 6,1197.

2. Spanoudakis, J.; Young, R. J. J Mater Sei 1984,19, 487.

3. Chikhi, N.; Fellahi, S.; Bakar, M. J App! Polym Sei 2001, 82, 861.

4. Bartlet, R; Paseauit, J. P.; Sautereau, H. J Appl Polym Sei 1985, 30,2955.

5. Kalfoglou, N. K.; Williams, H. L. J Appl Polym Sei 1973, 17, 1377.

6. Pearson, R. A.; Yee, A. F. J Mater Sei 1991, 26, 3828.

7. Kunz, S.C.; Sayre, J. A.; Assink, R. A. Polymer 1982, 23,1897.

8. Chikhi, N.; Fellahi, S.; Bakar, M. Eur Polym J 2002, 38, 251.

9. Sankaran, S.; Chanda, M. J Appl Polym Sei 1990, 39, 1635.

10. Hwang, J. F.; Manson, J. A.; Hertzberg, R. W.; Miller, G. A.; Sperling, J. H. Polym Eng Sei 1989, 29,1466.

11. Hedrick, J. L.; Yilgor, I.; Wilkes, G. L.; McGrath J. E. Polym Bull 1985,13, 201.

12. Frigione, M.; Acierno, D.; Mascia L. Adv Polym Technol 1999, $18,237$.
13. Hourston, D. J.; Lane, J. M.; MacBeath, N. A. Polym Inter 1991 $26,17$.

14. Rong, M.; Zeng, H. Polymer 1997, 38, 269.

15. Bakar, M.; Wojtania, I.; Legocka, I.; Gospodarczyk, J. J Adv Polym Technol 2007, 26, 223.

16. Basara, C.; Yilmazer, U.; Bayram, G. J Appl Polym Sei 2005, 98,1081 .

17. Messersmith, P. B.; Giannelis, E. P. Chem Mater 1994, 6,1719.

18. Lan, T.; Kaviratna, P. D.; Pinnavaia, T. J. Chem Mater 1995, 7, 2144.

19. Kornmann, X.; Lindberg, H.; Berglund, L. A. Polymer 2001, 42,1303 .

20. Wang, H. H.; Chen, J. C. Polym Eng Sei 1995, 35,1468.

21. Hsieh, K. H.; Han, J. L. J Polym Sei, Part B: Polym Phys 1990, 28, 623.

22. Harani, H.; Fellahi, S.; Bakar, M. J Appl Polym Sei 1998, 70, 2603.

23. Park, S. J.; Jin, J. S. J Appl Polym Sei 2001, 82, 775.

24. Bakar, M.; Duk, R.; Przybylek, M.; Kostrzewa, M. J Reinf Plast Compos 2009, 28, 2107.

25. Knott, J. F. In Fundamentals of Fracture Mechanics; Butterworths: London, 1976; pp. 130-132.

26. Kostrzewa, M.; Hausnerova, B.; Bakar, M.; Siwek, E. J Appl Polym Sei (in press).

27. Chen, B.; Evans, J. R. G. J Phys Chem B 2004,108,14986.

28. Jia, Q. M.; Zheng, M.; Chen, H. X.; Shen, D. J. Polym Bull 2005, $54,65$.

29. Jan, I. N.; Lee, T. M.; Chiou, K. C.; Lin, J. J. Ind Eng Chem Res 2005, 44, 2086.

30. Malucelli, G.; Bongiovanni, R.; Sangermanno, M.; Ronchetti, S.; Priola, A. Polymer 2007, 48, 7000.

31. Chen, B.; Liu, J.; Chen, H.; Wu, J. Chem Mater 2004, 16, 4864.

32. Park, J. H.; Jana, S. C. Macromolecules 2003, 36, 2758.

33. Bousmina, M. Macromolecules 2006, 39, 4259. 